\title{
La literatura oriental como campo de saber y de formación: un viaje estético y filosófico hacia la práctica del maestro*
}

Fecha de recepción: 22 de junio de 2018

Fecha de aprobación: 12 de noviembre de 2018

\section{Resumen}

En el marco de las Prácticas Profesionales de la Facultad de Educación de la Universidad de Antioquia, del pregrado de Licenciatura en Literatura y Lengua Castellana, este texto se propone el reconocimiento y la comprensión de la experiencia formativa que tuvo lugar en el Semillero de Formación de Literatura Oriental - Taller de los cerezos blancos- y en el ciclo de lecturas en voz alta -La hora interior-, ambos parte del proyecto de grado titulado El corazón en la punta del pincel: la literatura oriental desde una perspectiva estética y filosófica como aporte a la formación humanista. Se caracterizan ambos espacios, en tanto adquieren un sentido formativo donde el maestro en formación está en la posibilidad de construir saber pedagógico alrededor de la enseñanza de la literatura. De esta manera, se plantea la reflexión de cómo el maestro, en sus prácticas, interactúa con unos saberes culturales, literarios e históricos. Se espera concluir que la práctica, en los escenarios de los talleres en el semillero de formación y de las lecturas en voz alta, se posibilita como eje de reflexión, de construcción de saber y de indagación sobre otros modos de pensamiento.

Palabras clave: práctica pedagógica, literatura oriental, formación literaria, formación estética, formación pedagógica.

Citar: Pérez Uribe, W. (enero-junio de 2019). La literatura oriental como campo de saber y de formación: un viaje estético y filosófico hacia la práctica del maestro. La Palabra, (34), 179-190. (đot https://doi.org/10.19053/01218530.n34.2019.9543

\section{Wilson Pérez Uribe}

Universidad de Antioquia. Licenciado en Educación Básica con énfasis en Humanidades, Lengua Castellana. Artículos, ensayos y poemas suyos han sido publicados en España, México y Colombia. Obras: El amor y la eterna sinfonía del mar (Hombre Nuevo Editores, 2011); Movimientos (Universidad de Antioquia, 2018); La madeja y la estrella II: retratos de familia (Alapalabra, Universidad Central, 2018).

wilson.perezu@udea.edu.co

* Artículo de reflexión derivado del proyecto de investigación, El corazón en la punta del pincel: la literatura oriental desde una perspectiva estética y filosófica. Financiado por el Centro de Investigaciones Pedagógicas y Educativas (CIEP), de la Facultad de Educación, Universidad de Antioquia. 


\section{la palabra}

\section{Eastern Literature as Knowledge Field and Training: an Aesthetical and Philosophical Journey to the Teacher's Practice}

Within the framework of professional practices at the Faculty of Education of University of Antioquia and its Literature and Spanish undergraduate program, this paper intends the understanding and acknowledgement of the formative experience that took place in the Eastern Literature Training research group -White Cherry's Workshop- and the reading aloud cycle - The Internal Time-, both of them being part of the degree project named "The Heart on the Tip of the Brush: Eastern Literature from an Esthetical and Philosophical Perspective as a Contribution to the Humanistic Education". Both spaces are characterized as they acquire a formative sense, where the preservice teacher has the possibility to build pedagogical knowledge while teaching literature. Thus, it is raised the reflection on how the teacher, during their practices, interacts with some cultural, literary and historical knowledge. The conclusion expected is that the practice, at the workshops' sceneries in the training research group and the readings aloud, enables a reflection axis, construction of knowledge and inquiry, regarding other ways of thinking.

Keywords: pedagogical practice, eastern literature, literary training, esthetical training, pedagogical training.

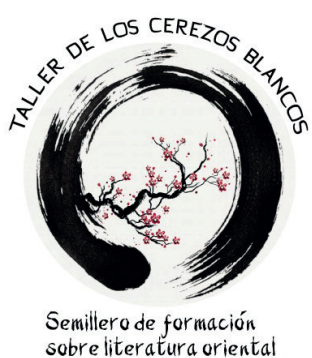

Moradas de la palabra: Taller de los cerezos blancos y La hora interior

Una vez que se cierra la puerta corredera, se colma la soledad.

- Ozaki Hōsai (1885-1926)

Pertenecer a un espacio para construir identidad. Ser parte de algo para que las palabras encuentren comunicación con otras palabras, con otras texturas, con otros gestos. El sujeto se configura como sujeto cuando interactúa con unos escenarios. Los escenarios son espacios para morar: habitar, permanecer, cultivar. En el marco del proyecto de grado titulado El corazón en la punta del pincel: la literatura oriental desde una perspectiva estética y filosófica como aporte a la formación humanista, la práctica profesional se fundamentó en dos escenarios: uno, Taller de los cerezos blancos, Semillero de formación de literatura oriental; otro, La hora Interior, Lecturas en voz alta sobre literatura oriental. Cuando los espacios son nombrados, la relación que establecemos con ellos tiende a cobrar un cierto sentido 
de intimidad, donde ya no somos extranjeros de paso, sino viajeros acogidos en la proximidad de una morada de palabras.

El acercamiento a la literatura oriental -en este caso nos hemos decantado por China y por Japón-, sin olvidar algunos asuntos estéticos de la India, implica un recambio de la mirada y un habitar del mundo desde otras consciencias.

En este sentido, tanto el semillero de formación, realizado en la Universidad de Antioquia y con extensión en la Sede Oriente de la misma; como las lecturas en voz alta realizadas en la Biblioteca Carlos Gaviria Díaz de la Universidad de Antioquia y en la Librería Grammata, posibilitan una configuración de escenarios con unas apuestas claras, en favor del proceso formativo propio de la práctica pedagógica.

El semillero de formación sobre literatura oriental, Taller de los cerezos blancos, se enmarca en el proyecto del Salón de la Palabra de la Facultad de Educación.

En el ámbito universitario, esta iniciativa surge como un pro- yecto pedagógico que genere dispositivos que conecten acción y reflexión por medio de las preguntas por la formación, los sujetos y el papel de la universidad en la sociedad. El Salón de la Palabra se potencia como un escenario universitario donde el quehacer del maestro en formación, dialoga con prácticas reflexivas alrededor de la construcción de saberes en favor de las dinámicas concretas de la sociedad.

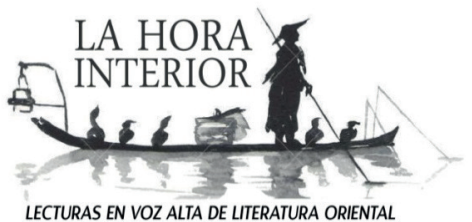

La hora interior se sustenta, como propuesta formativa, en torno a la lectura en vos alta, en dos escenarios: la biblioteca y la librería. La biblioteca es el gran epicentro de la investigación y el aprendizaje. Estudiar, leer y escribir son verbos de una misma aventura. Los espacios que congrega una biblioteca posibilitan un acercamiento íntimo y cercano con los libros. Hablar con otros y con uno mismo, es signo de que la lectura ha vehiculado palabras nuevas que deben ser dichas. La biblio- teca, entonces, se proyecta en la figura de receptiva escucha de esas otras palabras, porque no las condena ni las sanciona; las guarda, las protege; les da aire para su vuelo. La librería surge como un espacio abierto al público. Más que una invitación, es una congregación a la lectura y al diálogo en torno a la literatura oriental.

La librería es un territorio abierto al público, posibilita la conversación, el compartir y la lectura silenciosa. En este escenario, se fortalece el arte de leer juntos, cuyo rasgo de identidad es relacionar a personas de medios sociales muy diferentes (Petit, 2004).

La lectura en voz alta congrega, aúna, teje una voz colectiva en medio de la singularidad de cada sujeto. El texto se comenta, se propone ser inquietado, hacerlo enigma, desvelar sus secretos para que el público participe de él como de un nuevo mundo que requiere ser escuchado, hablado y comprendido.

A continuación presentamos la relación de los talleres y las fechas en las que tuvieron lugar en el marco del Semillero de formación: 


\begin{tabular}{|c|l|}
\hline 6 de marzo de 2018 & Revisitando Oriente y Occidente \\
\hline 13 de marzo de 2018 & Introducción a la literatura japonesa \\
\hline 20 de marzo y 3 de abril de 2018 & Período Heian y diarios en la literatura japonesa \\
\hline 10 de abril de 2018 & La poesía china y japonesa como experiencias de contemplación \\
\hline 17 de abril de 2018 & Introducción a la literatura china. Tradición del cuento chuanchi \\
\hline 24 de abril de 2018 & China: belleza y cultura \\
\hline 8 de mayo de 2018 & Filosofía oriental \\
\hline 15 de mayo de 2018 & Pintura: estética china y japonesa \\
\hline 22 de mayo de 2018 & Cine japonés: El cuento de la princesa Kaguya \\
\hline 29 de mayo y 5 de junio de 2018 & Acercamiento a la literatura china contemporánea \\
\hline 12 de junio y 19 de junio de 2018 & Acercamiento a la literatura japonesa contemporánea \\
\hline
\end{tabular}

Las obras literarias que nos ocuparon en voz alta, tanto en la Biblioteca Carlos Gaviria Díaz de la Universidad de Antioquia, como en la Librería Grammata, se relacionan a continuación.

\section{Lecturas en voz alta en la Biblioteca Carlos Gaviria Díaz La hora interior}

\begin{tabular}{|l|l|}
\hline 22 de febrero de 2018 & $\begin{array}{l}\text { Diarios en la literatura japonesa: "El libro de la almohada"; "El diario de la dama } \\
\text { Murasaki"; "El diario de la dama Izumi"; "Sueños y ensoñaciones de una dama"; } \\
\text { "Diario de una vagabunda". }\end{array}$ \\
\hline 8 de marzo de 2018 & Segundo capítulo de Jin Ping Mei: Flor de ciruelo en vasito de oro (China) \\
\hline 22 de marzo de 2018 & Primer capítulo de La novela de Genji, de Murasaki Shikibu (Japón) \\
\hline 5 de abril de 2018 & $\begin{array}{l}\text { Poesía china: Poemas de Li Po; poemas de la dinastía Sung; poesía contemporánea de } \\
\text { China. }\end{array}$ \\
\hline 19 de abril de 2018 & Poesía japonesa: tradición del haikú; poesía antigua y poesía contemporánea de Japón. \\
\hline 3 de mayo de 2018 & 101 cuentos zen, compilados por Nyogen Senzaki y Paul Reps. \\
\hline 17 de mayo de 2018 & Fragmentos del libro La importancia de vivir, de Lin Yutang (China). \\
\hline 31 de mayo de 2018 & Selección de Historias de la palma de la mano, de Yasunari Kawabata (Japón). \\
\hline 7 de junio de 2018 & El diario de un loco, de Lu Sin (China) \\
\hline
\end{tabular}

\section{Lecturas en voz alta en la Librería Grammata}

\section{La hora interior}

\begin{tabular}{|l|l|}
\hline 21 de febrero de 2018 & $\begin{array}{l}\text { Diarios en la literatura japonesa: "El libro de la almohada"; "El diario de la dama } \\
\text { Murasaki"; "El diario de la dama Izumi"; "Sueños y ensoñaciones de una dama"; } \\
\text { "Diario de una vagabunda". }\end{array}$ \\
\hline 7 de marzo de 2018 & Segundo capítulo de Jin Ping Mei: Flor de ciruelo en vasito de oro (China). \\
\hline 21 de marzo de 2018 & $\begin{array}{l}\text { El peso de una llama: poesía china y poesía japonesa. Un viaje entre lo clásico y lo } \\
\text { contemporáneo. }\end{array}$ \\
\hline
\end{tabular}




\begin{tabular}{|l|l|}
\hline 11 de abril de 2018 & Abandonarse a la pasión: relatos de Hiromi Kawakami. \\
\hline 25 de abril de 2018 & El diario de la señorita Sha Fei, de la escritora china Ding Ling. \\
\hline 9 de mayo de 2018 & 101 cuentos zen: asumir la vida en interdependencia con el orden natural de las cosas. \\
\hline 23 de mayo de 2018 & La importancia de vivir, de Lin Yutang. \\
\hline 6 de junio de 2018 & Historias de la palma de la mano, de Yasunari Kawabata. \\
\hline 20 de junio de 2018 & El diario de un loco, de Lu Sin. \\
\hline
\end{tabular}

El sentido formativo que dinamizó el trabajo en los dos escenarios, se enfocó en dos esferas: la formación literaria y la formación humanista desde lo estético y lo filosófico. Cuando hablamos de una formación literaria, teniendo en cuenta las experiencias vividas en ambos escenarios, referimos cómo cada quien hace memoria de su propio tiempo a la luz de la cultura, la historia y el arte. Cada quien construye el tiempo que destina al encuentro con la literatura, tal vez para ser menos sordos, menos mudos, y más sabios en silencios. Quien se relaciona con la literatura es un eterno aprendiz de la vida y de su tiempo vital. En lo que se refiere a la formación humanista, desde lo filosófico, en la línea de un pensamiento reflexivo sobre la vida. Desde lo estético, la formación humanista apunta también a un despertar sensible, en el sentido de posibilitar unas comprensiones, primero, sobre cómo se teje una tradición literaria desde su visión de mundo y los despliegues de la obra misma; segundo, sobre cómo los sujetos se apropian de saberes culturales para encauzar el horizonte ético de sus vidas a partir del cultivo de unas ciertas sensibilidades.

El maestro en formación no es ajeno a los escenarios donde dispone su saber didáctico, dialógico y de configuración de saber. El espacio habitado reclama una cierta disposición interior para que diga. Y el decir es detener el tiempo y eternizarlo en la forma luminosa del aprender. El semillero de formación, Taller de los cerezos blancos, implica una renovación de la mirada, en tanto se disponen unos textos, unos sonidos, unos colores para que otros ingresen a ese mundo. Las lecturas en voz alta de La hora interior, proponen para el maestro en formación, un espacio de conversación con personas que habitan los contextos cotidianos de la ciudad. Abre, entonces, la posibilidad del compartir una literatura que, para muchos, resulta extraña y desconocida. Son dos escenarios para que el maestro despliegue sus preguntas, sus certezas, sus temores; pero también para que comparta sus reflexiones y disponga otros lenguajes en favor de una formación holística; es decir, que no se agote en la interacción con la obra literaria, musical o pictórica, sino que trascienda a las dimensiones del ser, en tanto propicie un despertar sensible, una apertura de la conciencia hacia otras formas culturales, históricas y estéticas.

Habitante en devenir: el lugar de la estética y la filosofía oriental en la práctica pedagógica del maestro

En la jarra de agua flota una hormiga sin sombra.

- Yamaguchi Seishi (19011994)

María Zambrano, en un ensayo titulado "La mediación del maestro" (2011), reconoce que la cultura de Occidente se encuentra en una profunda crisis. Su reflexión atiende, también, a la idea de que las mediaciones a partir de las cuales esa cultura se moviliza, hacen parte de esa crisis. El lugar del maestro en las aulas y en otros espacios alternativos, como auténtico mediador de la cultura, adquiere la figura del artesano, en el sentido del cuidado, la atención y la responsabilidad de darle forma a un objeto. Sin duda alguna, en la interacción maestro estudiante, el saber como objeto cultural, 
participa en una dinámica de interpretaciones y comprensiones. En este sentido, ese carácter de dar forma, de orientar, de conversar, de acoger, en nuestros tiempos, precisa de una cierta oxigenación. Bien podríamos preguntarnos: ¿cómo se puede repensar la función mediadora del maestro a partir de los saberes estéticos y filosóficos que nos ofrece Oriente?

Entender la estética desde un despertar sensible, en el marco de la formación humanista, posibilita comprender las relaciones que establecemos con una manera particular de comprender el mundo desde Oriente que invita, ciertamente, a un entendimiento de nosotros mismos al entrar en contacto con objetos de creación artística como la poesía o la pintura. Chantal Maillard (2000) refiere que "[...] toda estética manifiesta una visión del mundo $\mathrm{y}$, por tanto, una determinada concepción de la realidad" (p. 62). Cuando consideramos la estética japonesa y la estética china, es posible preguntarnos por el pensar y el sentir. El modelo cartesiano nos enseñó a pensar; sin embargo, en las discusiones sobre el conocimiento y la percepción en estas culturas, debemos aprender a sentir. Con esta precisión, es dable considerar que la experiencia estética en el semillero de literatura oriental respondió a la comprensión continua de las bases estéticas que han configurado la visión del mundo y el sentido de los textos literarios. Si observamos con atención el lugar de la poesía, tanto en China como en Japón, nos enfrentamos a un asunto interesante: la tradición de la prosa como el eje de los gobiernos antiguos, así como el acto del amor y la vida cortesana, se regían por las prácticas de la escritura de la poesía. En este sentido, si consideramos los trazos que dieron forma a una lectura en voz alta y a un taller en el semillero, podemos plantear que la formación de un despertar sensible se propició, en tanto la función estética arraiga la idea de unas actitudes humanas que se ven reforzadas de acuerdo con unas dimensiones sensibles que implican una mirada espiral y no plana, una mirada del Todo y no parcializada sobre nuestro mundo, y, más importante, una mirada serena y atenta hacia el mundo interior.

El diálogo de saberes, la transdisciplariedad, la decolonización del conocimiento, ha supuesto discusiones necesarias en la formación de maestros. Las tensiones entre los saberes aceptados por la academia y la ciencia, y los saberes tradicionales que no han pasado por los filtros epistemológicos, sigue vigente. Castro Gómez (2007) anota, alrededor de esta tensión, que

[...] solamente son legítimos aquellos conocimientos que cumplen con las característi- cas metodológicas y epistémicas definidas a partir del mismo punto cero. Los demás conocimientos, desplegados históricamente por la humanidad durante milenios, son vistos como anecdóticos, superficiales, folclóricos, mitológicos, "pre-científicos" $\mathrm{y}$, en cualquier caso, como pertenecientes al pasado de Occidente (p. 88).

Que en la formación de maestros de lengua y literatura se posibilite el reconocimiento y la participación crítica y reflexiva de una tradición literaria, estética y filosófica en el contexto oriental, suscita otros modos de participación con esos saberes culturales que no han tenido un espacio preponderante en los currículos de nuestro país. Reorientar las prácticas lectoras y de escritura, desde una mirada más atenta, incluyendo otras perspectivas diferentes a la europea, incluso a la latinoamericana, incitaría a una formación en términos planetarios. Ser ciudadanos del mundo, desde una perspectiva humanista, implica la participación en otros discursos que bien pueden dinamizar las prácticas pedagógicas, irrigando los conocimientos sobre la literatura en términos de experiencia estética y de discusión sobre las crisis del mundo moderno a partir de otros saberes, en este caso, los asiáticos.

Pankaj Mishra (2014) anota: "Occidente siempre ha contemplado a Asia desde la estrecha 
perspectiva de sus propios intereses estratégicos y económicos, y no ha tomado en consideración -ni ha imaginado- las experiencias y las subjetividades colectivas de los pueblos asiáticos" (p. 30). El mundo Oriental se abre a la percepción. En sus fuentes yace una riqueza aún por explorar. Hay allí un cúmulo de experiencias por revisitar. Precisamos, de acuerdo con las anteriores reflexiones, de un encuentro -otro sobre la cultura oriental-, que no solo está albergada en su tradición literaria, sino también en sus filosofías y estéticas sobre el arte y el ser humano. Chantal Maillard (2000) sugiere que tal vez es importante que nuestra civilización occidental se aproxime a las vías de la sabiduría china para recuperar una forma de conocimiento que nuestra tradición científica desterró. Estos referentes nos abren la posibilidad de establecer diálogos epistémicos con esas otras formas culturales, históricas y estéticas de comprender el mundo. El orden del saber nunca está acabado, sino que se despliega a la manera de un rizoma, agenciando diversas miradas, otras voces, unos sentidos particulares, otros horizontes en favor de la formación de maestros de lenguaje y de estudiantes que ven en la literatura la posibilidad de participar del gran patrimonio de la humanidad, la cultura.

Ahora bien, es vital tornar la mirada hacia el campo de la fi- losofía oriental, y sus aportes a la práctica pedagógica, en tanto sugiere diálogos con la vida, el arte, la cultura y el devenir histórico. En esos campos se entrecruza la filosofía, toma de sí lo que puede dar; pregunta, a veces responde; siempre escucha y respira. La experiencia de textos como el Dhammapada, donde se recogen las enseñanzas del Buda, o Los capítulos interiores de Zhuang $\mathrm{Zi}$, pieza clave del taoísmo, o, incluso, ese texto de Takeuchi Yoshinori, "El existencialismo budista", cuya reflexión armoniza los lugares de la religión en la filosofía. Estos encuentros con la filosofía oriental permiten la reflexión continua sobre nuestra condición de habitantes de un tiempo, muchas veces, ajeno a la íntima conciencia de nuestro corazón. El lugar de la filosofía en el marco formativo de las prácticas pedagógicas, se entreteje en un espacio de reflexión y de discusión, donde importa más el aprender, el escuchar, que el dejar que nuestro $Y o$ haga su trabajo de manera "saludable". Un ejemplo luminoso de ello, tiene que ver con cómo el maestro despliega una serie de textos para pensar-nos el asunto del silencio. ¿A qué lugares se llegó?

En un artículo de María Teresa Román López, titulado "Reflexiones sobre el silencio y el lenguaje a la luz de oriente y occidente" (2012), se plantea que la humanidad se ha dejado llevar por el parloteo, donde el ruido no es más que una máscara y las palabras tienden a adormecer el mundo interior. Poco hemos advertido que entre la algarabía y el bullicio ensordecedor que han configurado ciertas comunidades de lenguaje, está el sonido oculto. La discusión alrededor del silencio, implicó una lectura de nuestra sociedad actual, donde, evidentemente, se tiende a calificar de extraño y de improductivo al que guarda silencio, al que se resguarda en sí mismo. Pero esta mirada hacia nuestra propia condición, de manera natural, llevó a considerar algunos valores tradicionales de Oriente, sobre todo de China y de Japón.

El monje tibetano Thich Nhat Hanh, en su libro Silencio. El poder de la quietud en un mundo ruidoso (2016), escribe que "el silencio interior es esencial para poder oír la llamada de la belleza y responder a ella" (p. 11). Con esto, el autor apunta a la idea de que nuestro mundo tangible empieza a relacionarse de una manera más cercana y más vivida con cada uno de nosotros. Sin embargo, estar en silencio no significa acallar las palabras o aislarnos de los otros. Se trata, más bien, de alertar los sentidos en una conciencia receptiva y plena, descubriendo así " [...] el vivo deseo de ayudar a los demás, de ser afectuoso y compasivo, de transformar el mundo para mejor" (p. 41). En el capítulo XXIII del Tao 
Te King (1994), se lee: "hablar poco es lo natural" (p. 37). Y en el capítulo XLV se dice que "la quietud pura es la regla del mundo" (p. 45). La percepción china sobre el silencio está arraigada a un fuerte vínculo con los mundos interiores y, como toda la filosofía del Tao, responde a las dimensiones de la vida práctica. Esas relaciones que se arraigan la noción del silencio con la quietud, la serenidad y la armonía, son lecturas casi perfectas de los ciclos de naturales.

El maestro, cómo se posiciona frente a estos saberes, cómo los presenta al mundo, cómo empieza a configurar su praxis. En el contexto de un taller de literatura oriental y de lecturas en voz alta, el hecho de encontrarnos con este tipo de reflexiones, sobre un asunto tan básico sobre el silencio, resulta interesante, para, si nos atrevemos a decirlo así, encender nuevas luces en medio de tantas agitaciones en tiempos actuales. A lo que queremos apuntar, es que el saber didáctico y disciplinar deben orientarse hacia un saber humano, en el sentido de que todo texto, toda obra de arte, toda apropiación sobre un sistema cultural, implicará una vuelta a las dimensiones más elementales de la vida. El escritor y pensador chino, Lin Yutang (1960), luego de releer las bases de la literatura y la filosofía chinas, concluye que el más alto ideal de la cultura china se basa en un sentido de desapego hacia la vida, asumiéndola con una mirada tolerante y un alto espíritu. "Sólo con este sentido de libertad y esta despreocupación llega uno eventualmente a la aguda, a la intensa alegría de vivir" (p. 16). Con esta reflexión queremos hacer énfasis en las condiciones de interacción, de enseñanza y de aprendizaje, que se pueden potenciar en un taller y en un ciclo de lecturas en voz alta. La apropiación de una obra literatura, el bordado de sentidos que se puede tejer alrededor de ella, atraerá el pensar y el sentir sobre la cotidiana fragancia de la vida.

De la literatura como campo de saber y de investigación a la figura del artista

\section{Revolotea \\ la mariposa amarilla sobre el agua.}

- Masaoka Shiki (1867-1902)

Si hemos hablado de estética y de filosofía oriental, ¿dónde está la literatura? Respuesta: tanto en China como en Japón, la filosofía, en tanto pensamiento reflexivo sobre la vida, y la estética, como una visión determinada del mundo, se han imbricado en la literatura, creando, así, la muestra de obras que se han preguntado por las influencias de las prácticas del Zen en la concepción de realidad del ser humano; otras indagan por la subversión de los valores confucianos en una sociedad en decadencia; otras proyectan la vida como un acto sagrado siguiendo la línea del aware y el ritmo vital; otras, se desdoblan contra una modernidad agresiva para reivindicar prácticas tradicionales.

Donald Keene (1953) señala que en la literatura japonesa hay belleza, riqueza y un encanto comunicativo que aún no se conoce en Occidente. Si bien esta afirmación es de hace más de medio siglo, ahora la producción editorial y los medios de comunicación han afianzado la difusión de obras literarias escritas en el País Naciente. Uno de los logros de Japón, anota Keene, es que supo modificar las grandes influencias chinas. En la literatura, la poesía difiere en gran medida de la escrita en China, las novelas surgen primero en Japón y uno de los grandes logros es el desarrollo del arte dramático (p. 12).

La literatura japonesa empieza a ser conocida por los occidentales por el auge que tuvieron las estampas del "mundo flotante". Fueron estas imágenes, durante gran tiempo, sustitutas de las obras literarias. Occidente ha recaído en un caso imperdonable: ha reducido su idea del Japón tradicional al despojo románticos de esas imágenes (Kasuya, 1968, p. 14). En esta vía de comprensión, es preciso entender la tradición literaria de Japón a partir de sus obras mismas, que abren un campo 
estético uniforme a partir de las primeras novelas, como el caso de La historia de Gengi o en la tradición poética, el haiku.

La literatura china goza de una tradición escrita desde la antigüedad. Los estudios sinológicos están cada vez más presentes, pero el acceso a las obras literarias sigue siendo un campo poco explorado. Se puede evidenciar en China la conservación de una integridad absoluta en los valores estéticos, en cuanto los héroes representativos no son jefes o guerreros, sino los sabios y los educadores (Kaltenmark-Ghéquer, 1952, pp. 1-2).

En el transcurso de los siglos, la literatura china ha dado prueba de una férrea conservación de su integridad. El prestigio de las letras siempre estuvo por encima del prestigio de las armas. En este caso, la tradición literaria empieza a definir una civilización cuya consigna se basa en el recuerdo de los legados de los antiguos sabios.

Estas breves anotaciones confirman un terreno literario aún por explorar. La sinuosidad de sus caminos requiere de una guía para su recorrido. Oriente, como se ha señalado, se propone como un contexto en términos socioculturales que debe ser leído desde una mirada abierta al asombro. Los marcos conceptuales que la justifican habrán de hacer hincapié en unos desarrollos históricos donde se vinculen literatura, filosofía y estética, sin olvidar que el asidero donde tendrían lugar es un marco de formación humanista. En este orden de ideas, es pertinente el preguntarnos: ¿qué relaciones propicia el maestro en su práctica con la literatura oriental? ¿Cómo aportan estas relaciones en la configuración de unos escenarios de saber y de investigación?

En lo que se refiere al maestro de literatura, Alfonso Cárdenas Páez (2004) anota que este debe reactivar los marcos de conocimiento de los estudiantes para ponerlo en diálogo con la naturaleza del texto. Asimismo, se deben encaminar procesos creativos en el ámbito de la creación literaria y el ensayo, con el propósito de potenciar habilidades de producción, interpretación y argumentación. En este orden de ideas, el maestro que pretenda enseñar literatura oriental atenderá a un conocimiento cultural, histórico y literario. Pero este es apenas un punto básico, porque el estudio inicial de la tradición literaria de Japón o de China, implica el desarrollo de un conocimiento de sí. No podemos olvidar que esta literatura tiene fuertes vínculos con sistemas de pensamiento que abogan por un aprendizaje del ser sobre sí mismo. Las relaciones que propicia el maestro se encaminan a un diálogo de las obras literarias con otros textos: música, pintura y cine. De igual manera, el diálogo se enfatiza en recrear las obras desde el plano histórico, filosófico y estético. Así, los aportes para una formación en el marco de la práctica pedagógica se orientan en dos vías, ninguna separada de la otra: hacia un saber de la vida y en la vida, en tanto somos sujetos históricos, éticos $\mathrm{y}$ con un accionar político con nosotros mismos y con nuestras comunidades; hacia un acontecimiento de la investigación, en tanto el saber aprendido debe ser puesto en tensión, como debe conversar con los tiempos modernos que habitamos, y, finalmente, este saber como un derecho que debe ser compartido en vías de una comprensión, pertinente y audaz, de nuestro lugar en el orbe planetario.

Louise Rosenblatt (2002) menciona que "la labor del maestro de literatura es propiciar interacciones fructíferas -0 , más precisamente, transaccionesentre los lectores individuales y las obras literarias individuales" (pp. 52-53). En este sentido, enseñar literatura oriental implica el diseño y la apropiación de un ambiente didáctico donde se potencie un acercamiento cognitivo y experiencial. Es preciso que el público que participa de un taller o de una lectura en voz alta reconozca que está haciendo parte de otra cultura, cuya literatura no es más que el reflejo de una condición de los valores humanos vistos a través de otros ojos. El taller de lite- 
ratura, construido con base en elementos estéticos del mundo de Oriente, resulta pertinente en tanto propicia interacciones de orden individual y grupal, focalizando las experiencias literarias como auténticos bordados de una vivencia donde han colindado pensamiento y emoción, razón y poesía, palabra y silencio.

Esto último nos lleva a considerar la figura del maestro de literatura como un artista, en el sentido de que debe tener un conocimiento de sí mismo para interactuar con las obras de arte y presentarlas a los otros para que estos se piensen a sí mismos. Ser artista es visualizar una gramática del acontecer, donde todos puedan habitar para reescribirla, reinventarla, cuestionarla, expandirla. En todo caso, es una gramática de la vida, del estar -ahora, ya, instante a instante- en la vida, con sus ritmos, sus azares, sus bellezas y sus horrores.

¿Qué actitud debe tomar el maestro en su práctica? ¿Desde dónde mirar para propiciar estos encuentros vitales con la literatura oriental en un escenario de taller y de lectura en voz alta? Para tejer una respuesta en torno a estas preguntas, vamos a conversar con la idea de método que plantea María Zambrano (2017) y la idea de actitud estética que plantea Chantal Maillard (2017). Maillard refiere que "artista es aquel que es ca- paz de percibir la simultaneidad de lo que ocurre. Ser artista es ver configurarse el (un) mundo, el mundo como objeto estético" (p. 227). Maestro artista, como le hemos planteado, en el sentido de que encuentra que todos los objetos del mundo están relacionados entre sí, como la literatura con la filosofía y la estética; la formación y el saber; la piedra con el río y la oruga con la rama. Maestro artista que sigue un método, un camino de los sentidos ensamblado en un ser estético, ético y político. Zambrano escribe:

Surge todo método de un instante glorioso de lucidez que está más allá de la conciencia y que la inunda. [...] Y así sólo el método que se hiciese cargo de esta vida, al fin desamparada de la lógica, incapaz de instalarse como su medio propio en el reino del logos asequible y disponible, daría resultado. Un método surgido de un "Incipt vita nova" total, que despierte y se haga cargo de todas las zonas de la vida (p. 125).

Se plantea, entonces, una actitud estética en términos de un aprender en el mundo cotidiano, asumiendo un método para encarar la vida desde la responsabilidad de los sentidos. Así, la labor del maestro de literatura se convierte en un acto creador en favor de la vida, como dice Zambrano, en el que se pueda hacer cargo de ella. En este sentido, la práctica afirma la experiencia en la que es, casi un deber, reflexionar sobre su condición formativa. El punto más exacto para mirar en torno a los encuentros en el taller y en las lecturas en voz alta, se centra en la posibilidad de interactuar con lectores diversos en el sano ofrecimiento de la literatura como vía íntima para vivir otras historias, para construir una identidad, para interrogar lo que hemos aprendido y, como escribe María Teresa Andruetto (2014) en una lectura de Estanislao Zuleta, para enfrentar nuestras carencias.

Aprender a mirar y a escuchar: actitudes para una conclusión

El sonido de las olas que se alejan y se acercan... Cuánto tiempo más viviré...

- Taneda Santōka (1885-1926)

Todo aprendizaje encarna un acontecimiento con la vida, la historia y la cultura. Ser parte de un tiempo común y compartido es el don secreto de las palabras. Las palabras nos acercan al lenguaje de lo incierto y al misterio de lo vivido. Pero las palabras necesitan de miradas y de oídos atentos para que su mensaje perdure. Cultivar-se implica anudar a la palabra la vitalidad de los sentidos. Entonces, lo que nos pasa, lo que nos acontece, puede ser susceptible de ser reflexionado y de darse a otros. Aprender a mirar y a escuchar significa, también, aten- 
der a una conciencia de sí que reconoce su propio trayecto. Aprender a mirar y a escuchar postula la idea de un reconocimiento de otros saber mirar y saber escuchar. De ahí deviene, primero, la actitud del maestro en formación que indaga sobre una literatura que no ha tenido un lugar en los currículos; segundo, el compromiso de la universidad del siglo XXI por tornar sus campos de investigación y de pensamiento hacia otras culturas.

El hecho de revisitar las relaciones entre los escenarios de práctica y la manera en que el maestro se apropia de ellos, nos permita afirmar que el saber no pertenece a las grandes esferas de la intelectualidad, sino que su construcción responde a unas dinámicas dialógicas entre el maestro, su apuesta didáctica y el compromiso por unas prácticas literarias aún desconocidas. En ese flujo de experiencias, el saber se transforma y se construye en la práctica, en tanto existan unos propósitos formativos y unas bases investigativas, anudado, claro está, a una actitud en términos éticos, estéticos y políticos por parte del maestro. Ética, desde un compromiso por los saberes culturales e históricos con los cuales se interactúa; estética, en la vía de una conciencia sobre el mundo que se reflexiona y que pasa por todos los sentidos; político, en tanto hay un posicionamiento sobre el tiempo en el que se habita, que se razona y se percibe.

El espacio de la práctica tejido alrededor de la literatura oriental cobra otros propósitos formativos que, entre otras cosas, se pregunta por las relaciones de un lector con la vida, el arte y la cultura. De esta manera, el saber que circula no se estanca en una cierta lógica del ser y del estar, sino, más bien de una conciencia estética de ese ser y de ese estar. Maillard (2017) la anota como una conciencia estética que "[...] habilita a la razón para que ésta construya mundos, esto es, para que con-forme la realidad y lo haga no mediante esquemas referenciales sino mediante esquemas presentativos" (p. 268). La práctica pedagógica se traduce en un escenario posible, no cerrado o limitado, para la recreación del mundo, la provocación de saberes de experiencia, la construcción de un proyecto de vida y la relación con una tradición literaria que invita a ser compartida en los espacios formativos de la universidad y de la escuela.

\section{Referencias}

Andruetto, M. T. (2014). La lectura, otra revolución. México: Fondo de Cultura Económica.

Cárdenas Páez, A. (2004). Elementos para una pedagogía de la literatura. Bogotá: Universidad Pedagógica Nacional.

Castro-Gómez, S. (2007). Deconolizar la Universidad: La hybris del punto cero y el diálogo de saberes. En S. Castro-Gómez \& R. Grosfoguel, El giro decolonial. Reflexiones para una verdad epistémica más allá del capitalismo global. Bogotá: Siglo del hombre Editores.

Kaltenark-Ghequier, O. (1952). La literatura china. Barcelona: Salvat Editores.

Kasuya, S. (1968). Japón: hacia una nueva literatura. Ciudad de México: El Colegio de México. 
Kenne, D. (1953). La literatura japonesa. Ciudad de México: Fondo de Cultura Económica.

Lin, Y. (1960). La importancia de vivir. Buenos Aires: Editorial Sudamericana.

Maillard, C. (2000). La sabiduría como estética. China: confucianismo, taoísmo y budismo. Madrid: Ediciones Akal.

Maillard, C. (2017). La razón estética. Barcelona: Galaxia Gutenberg.

Mishra, P. (2014). Las ruinas de las imperios. La rebelión contra occidente y la metamorfosis de Asia. Barcelona: Anagrama.

Nhat Hanh, T. (2015). Silencio. El poder de la quietud en un mundo ruidoso. Barcelona: Urano.

Petit, M. (2004). Lecturas: del espacio intimo al espacio público. Ciudad de México, México: Fondo de Cultura Económica.

Román López, M. T. (2012). Reflexiones sobre el silencio y el lenguaje a la luz de oriente y occidente. Revista Internacional de Filosofía, (56), 53-65.

Rosenblatt, L. M. (2002). La literatura como exploración. México: Fondo de Cultura Económica.

Zambrano, M. (2011). Filosofía y educación (Manuscritos). San Vicente, Alicante: Editorial Club Universitario.

Zambrano, M. (2017). Claros del bosque. Madrid: Ediciones Cátedra. 